\title{
Opinion paper: What needs to be changed for successful future livestock farming in Europe?
}

\author{
G. Busch ${ }^{1 \dagger}$, M. Gauly ${ }^{1}$ and A. Spiller ${ }^{2}$ \\ ${ }^{1}$ Faculty of Science and Technology, Freie Universität Bozen, Universitätsplatz 5, 39100 Bozen-Bolzano, Italy; ${ }^{2}$ Department of Agricultural Economics and Rural \\ Development, Georg-August-University of Goettingen, Platz der Göttinger Sieben 5, 37073 Göttingen, Germany
}

(First published online 20 June 2018)

The future success of the European livestock farming sector is at a critical stage, at least if success includes besides positive economic output, non-market values such as public acceptance of practices and sustainability issues, as we will do in this opinion paper. Discussions about the sustainability of livestock farming in Europe and other developed countries increasingly take ethics and the welfare of farmed animals into account. Especially in Northwestern-European countries such as the Netherlands, Germany or Denmark it looks as if the gap between public opinion about acceptable livestock farming and the state-of-the-art on farms is becoming wider despite the many efforts made by the sector to improve farm conditions for animals and communicate with the broader public. We argue that if livestock farming in Europe aims at keeping its license to produce in the long-run, the sector should adjust its strategy and strive an open dialogue with all stakeholders, including the public leading to fundamental changes in breeding, husbandry and management. The current criticisms may provide a chance for the European livestock sector to position itself as the moving force in animal welfare in order to lead the sector into a more animalfriendly and more sustainable future. However, badly managed, there is also the risk that the European livestock industry will decrease its importance instead of gaining a competitive advantage as a global animal welfare leader.

\section{Critiques regarding current livestock farming}

Many of the established production systems cause severe health and welfare problems for farm animals. There are examples of such deficits for many species. Impaired locomotion in dairy cow herds is often reported as being higher than $30 \%$ (von Keyserlingk et al., 2012), keelbone fractures and deviations in laying hens with prevalence between $56 \%$ and 97\% (Stratmann et al., 2015) or bursitis in fattening pigs kept on concrete floor with prevalence around 35\% (Meyer-Hamme

${ }^{\dagger}$ E-mail: gesa.busch@unibz.it et al., 2015) are some examples. In addition to health issues, the lack of natural environment, no access to outdoor or different climatic areas in barns form part of the critiques. Moreover, some practices are also related to ethical discussions about animals' integrity. This includes amputations that are related to pain such as dehorning in cattle, beak trimming in chicken, castration or tail docking in piglets. Further, specialized breeds lead to the production of unwanted counterparts such as male chicks in laying-hen production or male dairy calves. These practices are hardly understandable for lay people from the broader public. An altered human-animal relation, peoples' experience with companion animals, appreciation of genetic similarity between species including humans and an increase in pathocentric and biocentric ethics may be some of the reasons for the increasing demands towards livestock farming. If we consider livestock farming from a more holistic perspective, also environmental and global problems such as climate change have to be considered.

Against this, 'factory farming' and thus a perceived link between farm size on the one and animal care and welfare on the other side has been established as a powerful negative frame in the public debate about livestock farming.

\section{Sectors' strategies to encounter the criticisms}

The agricultural sector has been surprised once public criticisms came up and was largely unprepared for encountering these critiques. When public pressure further increased instead of disappearing, the sector started to react. Information campaigns about practices in livestock farming were initiated based on the assumption that experts in a field are right whereas lay people are wrong and that the public needs to learn about the real situations in order to accept current livestock farming. This approach, also known as the knowledge-deficit hypothesis, was a natural and understandable response to justify the development of animal husbandry. From the vantage point of the present, by doing so, an open dialogue about common goals of all 
stakeholders and about how to adjust and improve urgent issues in livestock farming without compromising farmers in an economically pressuring environment has been largely prevented. The chosen one-way communication (information transfer) excluded synchronization about values and aims between senders (agriculture) and receivers ('consumer citizens') of information. As a result, public critiques maintained and left many people in consternation about the perceived sector's ignorance of their concerns.

Experiencing tremendous public pressure that also heated up political debates about regulations in livestock farming (see e.g. the ban of battery cage systems for laying hens in the EU in 2012), forced the sector to address some of the 'hot topics' and to find solutions. However, measurements are merely passive. The sector only reacts instead of setting an own agenda. Thereby, the intended changes are often very conservative and deal with the curing of most urgent problems in existing systems. Problem definition and solutions are usually only defined within the sector. By doing so, essential public critiques and demands such as for example more naturalness in the animals' environment or ethical concerns related to common practices are largely left aside.

With regard to communication strategies from within the livestock sector, the emphasis is often put on the high efficiency of the breeds and the systems, the increasing (global) demand for animal proteins that need to be served and the domestic consumers' low willingness-to-pay. These aspects are made responsible for impeding the development of a more differentiated market for animal products apart from the standard (commodity) market that is mainly focused on low price, food safety, and food availability. In any case, addressing these issues highlight important aspects which need to be acknowledged, but they further show that the frame of reference for evaluating livestock farming from within the sector differs largely from that of many lay people. Common aims and values between the sector and the public are hardly visible which widens the gap and, at least partly, inhibits mutual understanding.

\section{How can future success be reached?}

The future of livestock farming in Europe is highly dependent on how agriculture will position itself in the public debate, how people will react both in their roles as citizens and consumers and how politics will respond to increasing public pressure. From our point of view, the livestock sector would be better off by changing its strategic orientation and communication (see also Spiller et al., 2015). Claiming costleadership as the main goal of European agriculture would be neither a realistic nor a promising strategy. In the longrun, countries in Northwestern Europe should change their competitive strategy towards new combinations of high technical efficiency with animal welfare leadership. Science and business are equally asked to provide on-farm solutions. Citizens' criticism should be viewed as an opportunity for a realignment of livestock production in Europe rather than a threat to current production. Production methods and practices will, as they always did, undergo change as it is the motor of development and innovation. Taking a pro-active and innovative position that initiates change towards a more animal friendly production would be a chance to regain public trust by implementing innovative and more appropriate systems. Such systems should also consider other improvements such as the reduction of greenhouse gas emissions from livestock farming through, for example genetics and breeding, of course, without compromising welfare enhancements and keeping possible trade-offs in mind. A tremendous reduction of total animal numbers is certainly a key point in the debates.

When it comes to the point as for how this can be practically reached, a combination of different activities seems promising. First, communication needs to be transformed from a one-way directional flow of information into a twoway engagement with the public that leads to innovative livestock farming ideas that are in line with widely held values within the public, but that also takes animal needs, farm economics, environmental aspects and farm structures into account. Scientific support of the process is recommended, especially for highlighting possible trade-offs.

Second, market approaches should underpin the activities. However, experience has shown a number of difficulties in the diffusion of animal welfare products, for example, high transaction costs in market niches or the problem of marketing all parts of an animal with price premiums. Regulatory shortcomings such as a lack of a common label are further barriers. And finally, the discrepancy between concerned citizens that worry about husbandry conditions and hedonistic consumers that also consider other aspects in their buying decisions such as taste, availability and price, to name only a few, partly avoids that public criticism is transformed into market demand on a larger scale. Therefore, policy instruments are additionally needed that incentivize the transformation of farming systems through, for example further increasing subsidies from the second pillar of the EU CAP. All in all, positioning livestock farming as welfare innovator from within the sector can be a successful strategy, at least for some pioneer countries like Denmark or the Netherlands, where the first sustainable innovations (e.g. labels) are emerging in the mass market. Demonstrating that public concerns are taken seriously by offering solutions for consumers in the market as well as supporting politics to give the right incentives are necessary steps forward to regain trust in the integrity of livestock farming within Europe that leads to success and advantages for many (including animals) in the long-run.

\section{Acknowledgments}

We thank two anonymous reviewers for their helpful comments that improved the quality of this paper.

\section{Declaration of interest}

There is no potential conflict of interest. 


\section{Ethics statement}

None.

\section{Software and data repository resources} None.

\section{References}

Meyer-Hamme S, Lambertz C and Gauly M 2015. Does group size have an impact on welfare indicators in fattening pigs? Animal 10, 142-149.
Spiller A, Gauly M, Balmann A, Bauhus J, Birner R, Bokelmann W, Christen O, Entenmann S, Grethe H, Knierim U, Latacz-Lohmann U, Matinez J, Nieberg H, Qaim M, Taube F, Tenhagen B-A and Weingarten P. 2015. Wege zu einer gesellschaftlich akzeptierten Nutztierhaltung. Berichte über LandwirtschaftZeitschrift für Agrarpolitik und Landwirtschaft, Sonderheft 221.

Stratmann A, Fröhlich EKF, Harlander-Matuschek A, Schrader L, Toscano MJ, Würbel $H$ and Gebhardt-Henrich SG 2015. Soft perches in an aviary system reduce incidence in keel bone damage in laying hens. PLOS ONE 10, e0122568.

von Keyserlingk MAG, Barrientos A, Ito K, Galo E and Weary DM 2012. Benchmarking cow comfort in North American freestall dairies: lameness, leg injuries, lying time, facility design, and management for high-producing Holstein dairy cows. Journal of Dairy Science 95, 7399-7408. 